\title{
Spectrum of Early Intervention Services for Children With Intrauterine Drug Exposure
}

\author{
Harolyn M. E. Belcher, MD, MHS; \\ Arlene M. Butz, MSN, ScD, RN; Pamela Wallace, PbD; \\ Alexander H. Hoon, MD, MPH; Elsie Reinbardt, CPNP; \\ Sharon A. Reeves, MAS, MSN, RN; \\ Margaret B. Pulsifer, PhD
}

Intrauterine illicit drug exposure may lead to a variety of adverse neurobehavioral and neurodevelopmental outcomes. Providing early intervention to reduce the impact of maternal substance abuse on the developing fetus may have significant benefits for the child and family. In this article, we report on 3 promising intervention programs designed to improve the well-being of parents with drug dependence and their children. The initiation of these programs spans from pregnancy through early childhood. All 3 programs are community-based, using comprehensive culturally relevant developmental models. The first program was developed to provide comprehensive care for pregnant women with drug dependence and their newborns. Project STRIVE (Support, Trust, Rehabilitation, Initiative, Values, and Education) provided substance abuse treatment, intensive center- and home-based social work, and parent education onsite at a high-risk obstetric and pediatric clinic. The second program, the Early Infant Transition Center, enrolled newborns with a history of neonatal abstinence syndrome and their mothers. Based in a renovated rowhouse in East Baltimore, one block away from a major urban hospital, the Early Infant Transition Center provided 24-hour nursing care, oncall physicians and nurse practitioners, social workers, parent education, and onsite sleeping accommodation for parents during their infant's recovery. The third program, Home-U-Go Safely, used community-based nurses to give home-based health monitoring, education, and support to new mothers with a history of cocaine and/or opiate dependence. Key words: early intervention, growth outcome, intrauterine drug exposure, maternal substance abuse, neurobehavior, neuromotor

From the Department of Neurology and Developmental Medicine, the Kennedy Krieger Institute (Drs Belcher, Butz, and Hoon, and Mss Reinhardt and Reeves), the Department of Pediatrics, the Jobns Hopkins School of Medicine (Drs Belcher, Butz, and Hoon), the Johns Hopkins Bloomberg School of Public Health (Dr Belcher), the Johns Hopkins University of Nursing (Ms Reeves), Baltimore, Md; and the Department of Psychiatry, Massachusetts General Hospital, Boston, Mass (Dr Pulsifer).

This work was supported by the National Institutes of Health grants $1 \mathrm{~K} 23$ MHO1822-01A1 and NR03442O1A1, and a Substance Abuse and Mental Health Services grant. We acknowledge Sherry Morgan, RN, and Tami $W$. Swearingen, $M A, R N$, for their roles in the development and management of the Early Infant Transition Center. Most important, we would like to thank the families who participated in these interventions.
7 ACH YEAR, an estimated 148,000 inhistory of intrauterine illicit drug exposure (IUIDE) (Substance Abuse and Mental Health Services Administration, 2002). Children with IUIDE are at risk for neurobehavioral disorders, language deficits, and school underachievement (Bandstra, Morrow, Anthony, Accornero, \& Fried, 2001; Bandstra et al., 2002; Butz et al., 2001; Chasnoff, Anson,

Corresponding author: Harolyn M. E. Belcher, MD, MHS, Department of Neurology and Developmental Medicine, Kennedy Krieger Institute, 707 N Broadway, Baltimore, MD 21205 (e-mail: belcher@kennedykrieger. org). 
Hatcher, Stenson, Iaukea, \& Randolph, 1998; Goldschmidt, Day, \& Richardson, 2000; Mayes, Grillon, Granger, \& Schottenfeld, 1998). While children with intrauterine alcohol and cigarette exposure have demonstrated decreased scores on intelligence tests (Goldschmidt, Richardson, Stoffer, Geva, \& Day, 1996; Larroque et al., 1995; Richardson, Ryan, Willford, Day, \& Goldschmidt, 2002; Streissguth, Barr, Kogan, \& Bookstein, 1996), most studies suggest that children with cocaine and opiate exposure perform comparably to their non-drug-exposed peers on measures of overall intelligence (Azuma \& Chasnoff, 1993; Chasnoff et al., 1998; Frank, Augustyn, Knight, Pell, \& Zuckerman, 2001; Hurt, Malmud, Betancourt, Brodsky, \& Giannetta, 2001; Pulsifer, Radonovich, Belcher, \& Butz, 2004; Richardson, Conroy, \& Day, 1996). Recent longitudinal studies of children with IUIDE document higher rates of externalizing (eg, inattention, aggression, disruptive behavior) and internalizing (eg, withdrawn, anxiety) behaviors (Bandstra et al., 2001; Butz, Pulsifer, Leppert, Rimrodt, \& Belcher, 2003; Butz et al., 2001; Chasnoff et al., 1998). In a study of 253 children with cocaine/polydrug exposure and 223 comparison non-drug-exposed children, children with cocaine exposure were more likely to exhibit dose-related deficiencies in sustained attention (Bandstra et al., 2001). In another large study of children with cocaine exposure, boys with cocaine exposure were twice as likely to have clinically significant scores for externalizing and delinquent behaviors by teacher report (Delaney-Black et al., 2000). In addition, children with intrauterine cocaine exposure were found to have cocaine-associated total language functioning deficits (Bandstra et al., 2002). Thus, IUIDE may be a preventable cause of behavior and language deficits during early childhood.

Drug dependence results from a complex interplay between the individual, the environment, and the drug. Drug dependence is often multigenerational. Remediable risk factors that predict drug dependence may be iden- tified in early childhood. Girls who grow up in a chaotic, unkempt, disorderly household with little emphasis on convention and religion are more likely to have later drug use (Block, Block, \& Keyes, 1988), while boys who lack self-control have a higher risk of later drug use. Women with a history of sexual abuse have a higher risk of drug dependence than their peers who were not sexually abused (Wilsnack, Vogeltanz, Klassen, \& Harris, 1997). Internalizing behaviors, for example, depression, anxiety, and withdrawn behaviors, during childhood are found more frequently in women who became drug dependent as adults (Luthar, Cushing, \& Rounsaville, 1996).

Early intervention for children with IUIDE may begin during gestation or immediately postpartum. Effective interventions should target both the child and the child's caretakers, utilizing coordinated interdisciplinary approaches that address parental and fetal status. Intervention strategies may include substance abuse treatment, high-risk obstetrical care, mental health counseling, parent education, periodic child-developmental evaluations, and therapeutic interventions when indicated. Over the course of 10 years, the primary author was involved with 3 such community-based intervention programs for children with IUIDE and their families. These programs utilized a range of services based on the needs of the family and available funding streams (Table 1). Most of the programs were supported with federal or private grant monies. This article will highlight 3 different approaches utilized by these programs to provide early intervention for parents who have a history of drug dependence and their children.

\section{INTERVENTIONS}

\section{Project STRIVE}

Project STRIVE (Support, Trust, Rehabilitation, Initiative, Values, and Education) was developed to provide comprehensive care for pregnant women with drug dependence 
Table 1. Description of services provided by Project STRIVE, Early Infant Transition Center, and the home-based nursing intervention-HUGS-program*

\begin{tabular}{|lccc|}
\hline Program services & $\begin{array}{c}\text { Eroject } \\
\text { STRIVE }\end{array}$ & $\begin{array}{c}\text { Transition } \\
\text { Center }\end{array}$ & $\begin{array}{c}\text { Home-based } \\
\text { nursing intervention } \\
\text { program (HUGS) }\end{array}$ \\
\hline Substance abuse treatment & $\mathrm{X}$ & & \\
Social work intervention & $\mathrm{X}$ & $\mathrm{X}$ & \\
Parent education & $\mathrm{X}$ & $\mathrm{X}$ & $\mathrm{X}$ \\
Home visits & $\mathrm{X}$ & $\mathrm{X}$ & $\mathrm{X}$ \\
Infant/child developmental intervention & $\mathrm{X}$ & $\mathrm{X}$ & $\mathrm{X}$ \\
Community-based services & $\mathrm{X}$ & $\mathrm{X}$ & $\mathrm{X}$ \\
& & & \\
\hline
\end{tabular}

${ }^{*}$ HUGS indicates Home-U-Go Safely.

and their newborns. Funded by a Substance Abuse and Mental Health Services Administration Pregnant Postpartum Women and Infants Grant (PPWI), Project STRIVE provided substance abuse treatment, parent education, intensive home- and center-based social work, obstetric and pediatric care onsite at a community-based high-risk obstetric and pediatric center, the University of South Florida Genesis Center for Obstetric and Pediatric Care (Genesis). The goals of the Project STRIVE were to (1) decrease drug use and improve maternal functioning, (2) improve birth and child developmental outcome, (3) improve family functioning, and (4) increase substance abuse awareness in the medical and lay community. Project STRIVE used a "onestop shopping" network of services housed at Genesis to address these goals. This innovative approach integrated services for both mother and child in a community-based teaching clinic for obstetric and pediatric residents.

Interdisciplinary program services for the mothers included intensive center- and homebased social services, addiction counseling (group and individual), and a culturally appropriate parenting curriculum developed by a local community agency, Child Abuse Council's Project Breakaway. Social workers primarily focused on maternal mental health, building healthy sober relationships, housing, and employment issues. Each social worker carried a caseload of no more than 15 clients. Specific social work interventions included in- tensive case management, individual and family mediation, group work activities to promote psychosocial wellness and to address issues related to daily living experiences, and community and vocational training referrals. Two additional mental health providers, including a psychiatrist specializing in the treatment of women during pregnancy and substance abuse, were also available to provide evaluation, crisis intervention, and medication monitoring. The parent educator provided group lessons, as well as home visits after the infant was born, to model desired parenting behaviors. Ongoing home visits began after birth of the child and occurred biweekly during the first 2 months, monthly during the second to the sixth months, and at least bimonthly from the sixth to the twelfth the months.

\section{Methods}

\section{Sample}

Between April 1992 and December 1995, 80 women were enrolled in the program. Polydrug use was reported by the majority of women (55\%), while cocaine/crack was the primary drug of choice in over 3 quarters of the enrollees (77\%). Approximately $57 \%$ of the participants admitted to current alcohol use upon entry to the STRIVE program and approximately $18 \%$ of the mothersto-be smoked tobacco. The mean maternal age at the time of program entry was 
Table 2. Maternal demographics for Project STRIVE participants $(N=79)$

\begin{tabular}{|lccc|}
\hline Characteristic & \% & Mean & Range \\
\hline Age at entry, y & & 28.1 & $20-39$ \\
Race/ethnicity & 63.3 & & \\
African American & 30.4 & & \\
White & 3.8 & & \\
Hispanic & 2.5 & & \\
Other & 33.8 & & \\
Completed high school or above & & & \\
Years of education & 75.9 & & \\
Federal assistance & 79 & & \\
History of criminal arrest & 55 & & \\
Polydrug use & 77 & & \\
Cocaine/crack use & 60 & & \\
Tobacco use & 52 & & \\
Psychiatric diagnosis & 80 & & \\
History of physical violence & 71 & & \\
History of sexual abuse & & & \\
&
\end{tabular}

28.1 years $($ range $=20-39$ years) $($ Table 2$)$. Most women were never married (59.5\%). Sixty-three percent of the women were African American, 30.4\% were White, 3.8\% were Hispanic, and $2.5 \%$ were from other racial and/or ethnic groups. Almost two thirds (66.2\%) of the women who enrolled in Project STRIVE had not completed high school.

In general, the mothers reported the use of alcohol or marijuana several years before using cocaine. The typical client began using alcohol and/or marijuana as a teenager. Mean age of initial alcohol use was 15.8 years (range 5-26 years), while mean age of initial marijuana use was 16.2 years (range $=$ 6-25 years). The mean age for initiation of cocaine or opiates was 20.5 years (range $=$ 12-33 years). The reason for initial drug use was primarily experimentation (25.3\%), followed by peer/social pressure (10.7\%) and depression (9.3\%). Fifteen children with IUIDE who were discharged from the hospital into a church-based foster care program were used to compare birth growth parameters. Race, Apgar scores at 1 and 5 minutes, and gestational age did not differ between the children in the STRIVE program versus the children in foster care (Table 3). Infants were placed in foster care because of the local child abuse statutes in the 1990s that required infants to be placed in foster care if their mothers had a positive urine drug screen for illicit drugs during pregnancy, without a history of drug treatment. Two of the authors (H.B. and P.W.) provided evaluations for children and education for the foster and biological parents in the church-based foster care program as a free community service.

\section{Procedures and statistical metbods}

Each subject was assigned a random number. Data were recorded and entered into a computer database using a random number to identify the case. Demographic information, drug use information by interview and random drug screen, perinatal and maternal medical history, birth outcome, and program participation data was collected. The Beck Depression Inventory (Beck, Ward, Medelson, Mock, \& Erbaugh, 1961), Adult Adolescent Parenting Inventory (Bavolek, 1990), Child Abuse Potential Scale (Milner \& Wimberley, 1979) Parenting Knowledge Scale (Child Abuse Council, 1992), Bayley Scales of Infant Development (Bayley, 1969), and Bayley Scales of Infant Development-second edition (Bayley, 1993) for children born after the publication of the second edition. The data set 
Table 3. Birth outcome for STRIVE versus foster care children with intrauterine drug exposure*

\begin{tabular}{|c|c|c|}
\hline Birth outcome & $\begin{array}{l}\text { STRIVE infants } \\
\quad(n=57)\end{array}$ & $\begin{array}{c}\text { Foster care } \\
\text { infants }(n=15)\end{array}$ \\
\hline Apgar $1 \mathrm{~min}$ & 7.88 & 7.77 \\
\hline Apgar 5 min & 8.71 & 8.80 \\
\hline Gestational age by date, wk & 38.14 & 35.77 \\
\hline Gestational age by examination, wk & 37.86 & 36.46 \\
\hline Birth weight, $\mathbf{g}^{\dagger}$ & 3000.42 & 2274.47 \\
\hline Birth length, $\mathrm{cm}^{\ddagger}$ & 47.54 & 44.52 \\
\hline Head circumference, $\mathrm{cm}^{\ddagger}$ & 33.61 & 31.66 \\
\hline Neonatal complications & $n(\%)$ & $n(\%)$ \\
\hline Human immunodeficiency virus positive ${ }^{\dagger}$ & $0(0)$ & $3(20)$ \\
\hline Apnea ${ }^{\ddagger}$ & $2(3.5)$ & $0(0)$ \\
\hline Mechanical ventilation $\ddagger$ & $2(3.5)$ & $1(6.6)$ \\
\hline Intraventricular hemorrhage ${ }^{\ddagger}$ & $1(1.8)$ & $1(6.6)$ \\
\hline Low birth weight ${ }^{\dagger}$ & $10(17.5)$ & $9(60)$ \\
\hline
\end{tabular}

\footnotetext{
${ }^{*} t$ test used for birth outcome and Mann-Whitney $U$ test for nonparametric neonatal complication data.

$\dagger P<.001$.

$\ddagger P<.05$.
}

was analyzed using descriptive statistics. Frequency distribution, mean, and standard deviation for psychological measures were calculated. $t$ Test analysis was used to compare birth growth parameters of children in the STRIVE program versus children with IUIDE who were in foster care. Chi-square analysis was used to compare groups on categorical measures. Mann-Whitney $U$ test was used for nonparametric data. All reported $P$ values used 2-tailed tests of significance.

\section{Maternal outcome}

Eighty percent of women who answered questions regarding physical abuse $(n=54)$ reported that they had experienced physical violence. Fifteen percent had experienced violence as a child. Thirty-seven percent of the mothers-to-be had experienced violence at the hands of their partner. Over half of the women $(63 \%)$ had a history of forced sexual activity; $48 \%$ had experienced sexual abuse during childhood. By the time of discharge, 41 of the 80 women had received, or had a suspected, comorbid psychiatric diagnosis.
On the average, the 80 women received 43.4 (SD $=46.3$ ) hours of social work intervention, $59.9(\mathrm{SD}=39.0)$ hours of addiction counseling, $34.7(\mathrm{SD}=43.8)$ group substance abuse sessions, and $24.8(\mathrm{SD}=31.8)$ parenting sessions. Mean length of stay for women enrolled in Project STRIVE was 132.6 days ( $\mathrm{SD}=127.2$ days; range $=1-420$ days). Of the 80 clients, only $20 \%$ were considered successful. Slightly over $13 \%(n=11)$ completed all requirements necessary for graduation (mean number of program days for this group was $300.2)$ and $6.5 \%(n=5)$ received maximum benefit and were considered successful participants (mean number of program days was 318). Reasons for discharge included transfer to more specialized program $(n=8)$. Reasons beyond participant's control (eg, incarceration or moved out of area) $(n=8)$. Approximately one quarter of the participants were unengaged, never fully participating in the services $(n=21)$, and $33.7 \%(n=27)$ were discharged for failure to complete one or more program components.

During the program, participants were given random urine drug screens. The mean 
number of drug screens per participant was 14.3 (range $=0-107$ ). The mean number of positive urine drug screens was less than 1 per participant $($ mean $=0.8$; range $=0-8)$. Perinatal information was complete on 55 Project STRIVE participants; of these women, more than, $75 \%(76.4 \%)$ had a negative drug screen at the time of labor.

The Adult Adolescent Parenting Inventory (AAPI; Bavolek, 1990) was used to evaluate the change in parent-child functioning over the course of the intervention. The most striking difference noted was the decreased use of corporal punishment. There was a statistically significant improvement in the corporal punishment subscale, indicating the mothers, rather than using corporal punishment, had developed alternative discipline strategies (Table 4). Only slight improvement was noted in the inappropriate expectations and lack of empathy subscales. The unchanged score on the role reversal subscale suggests that many of the mothers use their children to provide emotional comfort for themselves; thus, this remained an area where the mothers were still at risk. A measure of parent knowledge developed by Project Breakaway (Child Abuse Council, 1992) was used to evaluate comprehension of the parent education objectives (Table 5). The Child Abuse Potential Scale (Milner \& Wimberley, 1979) and Beck Depression Inventory (Beck et al., 1961) were used to measure potential for abuse and maternal depression, respectively. Statistically signifi-

Table 4. Mean Adult Adolescent Parenting Inventory pretest and posttest scores for Project STRIVE participants

\begin{tabular}{|lcc|}
\hline Measure & Pretest & Posttest \\
\hline Inappropriate & 5.7 & 5.8 \\
$\quad$ expectations & & \\
Lack of empathy & 5.2 & 5.6 \\
Corporal punishment & 5.8 & $7.2^{*}$ \\
Role reversal & 3.9 & 3.9 \\
& & \\
\hline
\end{tabular}

${ }^{*} P<.05$.
Table 5. Mean Child Abuse Potential (CAP) Scale, maternal depression, and parent knowledge scores for Project STRIVE participants

\begin{tabular}{|lcc|}
\hline Measure & Pretest & Posttest \\
\hline CAP & 251.6 & 206.8 \\
Beck depression & 21.1 & $4.1^{*}$ \\
$\quad$ inventory & & \\
Parenting knowledge & 59.7 & $87.9^{\dagger}$ \\
\hline
\end{tabular}

$* P<.01$.

${ }^{\dagger} P<.001$.

cant improvements were noted in both parent knowledge and depression (Table 5).

\section{Cbild outcome}

Mean birth weight was $3000.4 \mathrm{~g}$, mean length at birth was $47.5 \mathrm{~cm}$, and birth head circumference was $33.6 \mathrm{~cm}$ for children whose mothers were enrolled in the STRIVE program (see Table 3). These measures were significantly larger than for infants born in the same hospital who were drug exposed and whose mothers were not enrolled in the STRIVE program $(P<.01, P<.05$, and $P<.05$, respectively). Infants born to the mothers in the STRIVE program had significantly less neonatal complications. Mean Bayley Scores Mental Developmental Index (MDI) (Bayley, 1969, 1993) for children in the STRIVE program were at $100.9(\mathrm{SD}=21.5)$ for infants less than 6 months old, 103.2 ( $\mathrm{SD}=14.6$ ) for children 6 to 12 months old, and $92.8(\mathrm{SD}=6.5)$ for children 12 to 18 months old. Scores on the Bayley Scales of Infant Development were in the average range for children born to mothers in the STRIVE program.

\section{Community outcome}

Over the 4 years of the grant period, 59 community awareness activities were held. These activities included community health fairs, pediatric and obstetric grand rounds, resident training activities, church-based educational sessions and health fairs, and conferences for city human services agencies. Activities were individually designed for the 
target audience. Consultants from Howard University College of Medicine developed a cultural competency curriculum to address issues related to providing services for multicultural pregnant women with drug dependence for the University of South Florida's Departments of Obstetrics, and Gynecology and Pediatrics. More than 9000 individuals participated in community awareness activities and more than 7000 individuals participated in the educational activities sponsored by Project STRIVE.

In summary, mothers who participated in Project STRIVE received intensive integrated services both in the home and in the clinic where they received prenatal and pediatric care. Improvements were noted in maternal parent knowledge and depression. While the majority of mothers did not complete the entire program outlined by Project STRIVE, the infants born to the mothers in the program had significantly improved fetal growth, as demonstrated by larger birth growth parameters. Mean child development scores were in the average range. Physicians, residents, students, and community members were provided enhanced education regarding substance abuse treatment and prevention.

\section{Early Infant Transition Center}

The Kennedy Krieger Institute's EITC was developed in response to the Baltimore community need for comprehensive medical and social services for high-risk infants, especially those experiencing neonatal abstinence syndrome in a managed care environment. Babies with neonatal abstinence syndrome often face a dual risk from biologic and environmental factors. Mothers with drug dependence may not have access to or avail themselves of quality prenatal care. Concurrent environmental and health concerns such as poverty, physical abuse, poor nutrition, homelessness, and lack of routine medical care may contribute to the increased risk of premature and/or underweight births and subsequent developmental and behavioral problems that children may experience.
Fortunately, today, there are medical and therapeutic interventions that can greatly improve the chances that these infants will not only survive but thrive. The challenge is finding a service model that is accessible to families, delivers the appropriate services to the infant, and does so in a manner that third-party payors will support. Owing to the trend of shorter hospitalizations, managed care organizations find that early hospital discharge programs are a more cost-effective option. The literature is devoid of community-based care delivery models for this population of children with neonatal drug withdrawal. Thus, the EITC Program was developed through replication of portions of established and effective models, adding components to enhance the effectiveness of the caregiver's role and his or her relationship with the infant.

The EITC was developed as a familycentered and community-based, medically supervised program for high-risk term and preterm infants who were preparing for discharge from an acute care setting, but were not medically ready to go directly home. The Center is located in a renovated 3-story brick row house in the East Baltimore community. It is strategically located one block from a pediatric emergency room of a large teaching medical facility. Most infants were referred from neonatal intensive care units, pediatric intensive care units, newborn nurseries, and pediatric units.

The nurse-managed center had a boardcertified neonatologist who served as the Medical Director. A pediatric nurse practitioner coordinated the care of these infants under the direction of the Medical Director. The day-to-day operations were managed by a nurse clinical care coordinator. The EITC staff included registered nurses with neonatal intensive care unit experience, specially trained nursing assistants, and a clinical social worker. Criteria for admission to the program included a minimum weight of $1400 \mathrm{~g}$, no contagious disease, medically stable to leave an acute care hospital, and an identified caregiver who would participate in the care and assume responsibility for the infant upon 
discharge. Infants treated at the EITC were considered subacute, for example, infants with neonatal drug withdrawal syndrome or stable premature infants who needed assistance and monitoring with feeding and growth. Infants who experienced acute illness or potentially life-threatening complications were transferred to an acute care facility until the acute issues were addressed.

Interdisciplinary patient rounds were conducted 3 times per week and were attended by the medical staff as well as nurse, nurse coordinator and social worker on a regular basis with consultative staff such as the oral-motor specialist, attending on an as-needed basis. The medical director provided on-call services after regular work hours and on weekends and holidays. Infants with neonatal drug exposure were initially managed based on the treatment guidelines of the Substance Abuse and Mental Health Services Administration Center for Substance Abuse Treatment (Department of Health and Human Services, 1995). Since the house admitted infants from a number of hospital nurseries, many of the babies had already been started on specific pharmacologic therapy. Paregoric or phenobarbital were most often prescribed and continued during the admission to the EITC. On the basis of the clinical symptoms, a second medication such as phenobarbital was added in a small number of infants for severe central nervous symptoms or paregoric for increasing gastrointestinal signs.

Pharmacological management was reevaluated after the American Academy of Pediatrics published recommendations for management of neonatal drug withdrawal (American Academy of Pediatrics Committee on Drugs, 1998). Deodorized tincture of opium became the preferred medication for most of the infants treated with opiate withdrawal owing to the higher alcohol and additive content of paregoric.

The EITC social worker and nursing staff also focused on intensive caregiver training and education. All parents or caregivers participated in teaching including viewing video- tapes and nursing-directed education focusing on substance abuse withdrawal information and management and routine well-baby care. Three rooms were available to primary caregivers for rooming-in in this homelike setting. Parents were encouraged to remain for at least 2 overnight stays prior to discharge. Most caregivers stayed more than the recommended 2 nights. Caregivers were required to demonstrate competency in well-baby care. Parent participation in the planning, care, and treatment of the infant was an expected outcome of the program.

\section{Methods}

\section{Sample}

Data on the first 46 infants treated for narcotic abstinence syndrome in the EITC Program are described in this article. Informed consent was obtained from the parent for the expanded neonatal neurological examination. The protocol was reviewed and approved by the Johns Hopkins Medical Institutional Review Board. Demographic and drug use histories were obtained through interview of the mother and/or review of her medical record (Table 6).

\section{Procedures and statistical methods}

Efforts were made to limit overstimulation of the infants, including using muted light, extended quiet periods or soft music, and swaddling (Forrest, 1994). Prior to each feeding, an adaptation of the Finnegan Neonatal Abstinence Scoring System (Finnegan, Kron, Connaughton, \& Emich, 1975) was performed to document symptoms of withdrawal, including duration of sleep, tone and feeding abnormalities, and tremors. Growth parameters were monitored at routine intervals and tracked daily for weights and weekly for length and head-circumference measurements using standardized growth charts. The infant's neurobehavioral status was closely evaluated through regular examinations, by review of the Neonatal Abstinence Scoring System (Finnegan et al., 1975) and, in a subgroup of babies, by using an expanded neurological evaluation, including the 
Table 6. EITC Participants: Maternal demographics $(n=46)^{*}$

\begin{tabular}{|lccc|}
\hline Characteristics & \% & Mean & Standard deviation \\
\hline Maternal age, $y$ & & 30.1 & 4.5 \\
Paternal age, $y$ & & 36 & 10.6 \\
Race & 89 & & \\
$\quad$ African American & 11 & & \\
White & & & \\
Marital status & 82 & & \\
Single & 5 & \\
$\quad$ Married & 5 & \\
Widowed & 8 & \\
$\quad$ Divorced/separated & 19 & \\
Maternal education & 39 & \\
9 y or less & 29 & \\
10-11 y & 13 & \\
High school/GED & 45 & \\
$\quad$ Some college/vocational school & & \\
History of incarceration (positive) & & \\
\end{tabular}

*EITC indicates Early Infant Transition Center; GED, general educational development.

Dubowitz Neonatal Neurologic Exam (Dubowitz \& Dubowitz, 1981) and the Brazelton Neonatal Behavioral Assessment Scale (Brazelton, 1984). Well-baby care was provided on the basis of the guidelines of the American Academy of Pediatrics. One hundred percent of the infants received initial immunizations and newborn screening as well as follow-up laboratory testing as needed. A primary care provider was identified and appointments made for a well child checkup prior to the planned discharge. Community referrals were also made with resources such as the Infants and Toddlers Program and WIC. A copy of the discharge summary was forwarded to the primary care provider before the scheduled appointment. Pediatric primary care providers were identified and initial follow-up appointments were made by the time of discharge for all infants.

The data set was analyzed using descriptive statistics. Frequency distribution, mean, and standard deviation for psychological measures were calculated. $t$ Test analysis was used to compare birth growth parameters of children in the EITC program to a normative US population (Foye \& Sulkes, 1990). All reported $P$ values used 2 -tailed tests of significance.

\section{Infant outcome}

At the time of discharge, statistically significant improvements (weight: $t$ statistic $=4.2$, $P=.0001$; head circumference: $t$ statistic 2.1 ; $P<.05)$ were noted in the infant's weight and head circumference when compared to the expected growth rates for non-drug-exposed infants of a similar gestational age (Foye \& Sulkes, 1990) (Table 7). Medical diagnoses identified in the nursery prior to transfer or established during the EITC admission included heart murmur, congenital syphilis, and dermatitis. One infant with drug withdrawal had severe oral motor abnormalities that required nasogastric feeding on admission. With medication management and intensive oral motor intervention (eg, occupational therapy), the infant's symptoms resolved. Baseline neurological assessments are summarized on 32 infants enrolled in the EITC program in Table 8. Frequent neurologic symptoms included hypertonia, disturbed and undisturbed 
Table 7. EITC participants: Infant demographics $(n=46)^{*}$

\begin{tabular}{|c|c|c|c|c|}
\hline Characteristics & $n$ & Mean & Standard deviation & $\%$ \\
\hline Birth weight, $g$ & 45 & 2716.0 & 467.6 & \\
\hline Birth length, $\mathrm{cm}$ & 42 & 47.0 & 4.7 & \\
\hline Birth head circumference, $\mathrm{cm}$ & 40 & 32.5 & 1.8 & \\
\hline Gestational age, $\mathbf{w}$ & 44 & 38.5 & 1.7 & \\
\hline \multicolumn{5}{|l|}{ Neonatal urine drug screen results } \\
\hline Opiate & & & & 88 \\
\hline Cocaine & & & & 73 \\
\hline Marijuana & & & & 3 \\
\hline Age at admission, $\mathrm{d}$ & 46 & 9.7 & 8.0 & \\
\hline Admission weight, $\mathrm{g}$ & 45 & 2721.1 & 413.0 & \\
\hline Discharge weight, $\mathrm{g}$ & 44 & 3769.4 & $699.2^{\dagger}$ & \\
\hline Admission length, $\mathrm{cm}$ & 44 & 48.0 & 2.8 & \\
\hline Discharge length, $\mathrm{cm}$ & 44 & 50.2 & 4.8 & \\
\hline Admission head circumference, $\mathrm{cm}$ & 42 & 33.0 & 1.6 & \\
\hline Discharge head circumference, $\mathrm{cm}$ & 42 & 35.6 & $1.5^{\ddagger}$ & \\
\hline Duration of EITC stay, $d$ & 46 & 39.2 & 58.3 & \\
\hline
\end{tabular}

*EITC indicates Early Transition Infant Center.

${ }^{\dagger} t$ statistic $=4.2 ; P=.0001$.

${ }^{\ddagger} t$ statistic $=2.1 ; P<.05$.

tremors, hyperactive Moro and irritability (see Table 8). Less commonly, myoclonic jerks were exhibited by predominately methadoneexposed infants. One infant was evaluated for possible seizure activity with a workup, including a brain CT scan and EEG that were normal. Our experience with the neurological findings of drug-exposed infants was consistent with those documented in the literature (Belcher et al., 1999; Bell \& Lau, 1995; Chiriboga, Brust, Bateman, \& Hauser, 1999; Kaltenback \& Finnegan, 1986; Morrow et al., 2001). At discharge from the EITC, the majority of infants were found to have persistent mild neurological symptoms such as hypertonia and intermittent irritability. A small percentage were noted to have moderate findings such as increased extensor tone, oral motor abnormalities related to tone, and persistent tremor.

\section{Maternal outcome}

Mothers and children who participated in the EITC program seem to benefit from the comprehensive community-based medical services provided in a homelike environment. Infants with IUIDE grew faster than the expected rate for full-term nonexposed infants. Parents received individualized counseling, parent education, drug treatment, and follow-up pediatric care referrals to promote the well-being of their new infant as well as themselves.

\section{Home-U-Go Safely}

The HUGS community-based intervention program provided home-based nursing intervention for children with illicit drug exposure. Funded by a National Institutes of Health grant, The HUGS program used a randomized design to study the impact of home-based nursing intervention on children who had illicit drug exposure versus the standard of care for children with IUIDE. The intervention model utilized specially trained community health nurses to (1) monitor infant health and growth, (2) provide mother/caregiver developmental information and emotional sup- 
Table 8. Baseline neonatal neurologic summary for children in EITC program $(n=32)$

\begin{tabular}{|lr|}
\hline Variable & $\boldsymbol{n}(\%)$ \\
\hline Upper extremity tone & \\
Normal & $12(38)$ \\
Suspect & $9(28)$ \\
Abnormal & $11(34)$ \\
$\quad$ Hypertonic & $5(25)$ \\
Hypotonic & $15(75)$ \\
Lower extremity tone & \\
Normal & $19(59)$ \\
Suspect & $8(25)$ \\
Abnormal & $5(16)$ \\
$\quad$ Hypertonic & $3(27)$ \\
Hypotonic & $8(73)$ \\
Axial tone & \\
Normal & $18(56)$ \\
Suspect & $9(28)$ \\
Abnormal & $5(16)$ \\
Hypertonic & $1(7)$ \\
$\quad$ Hypotonic & $13(93)$ \\
Visual responsiveness & \\
Normal & $18(56)$ \\
Suspect & $8(25)$ \\
Abnormal & $6(19)$ \\
Auditory responsiveness & \\
Normal & $20(63)$ \\
Suspect & $10(31)$ \\
Abnormal & $2(6)$ \\
State regulation & \\
Normal & $19(59)$ \\
Suspect & $6(19)$ \\
Abnormal & $7(22)$ \\
& \\
\hline
\end{tabular}

port, and (3) teach the use of a Snugli, frontworn papoose, to promote mother-child contact (Butz, Lears, O'Neil, \& Lukk, 1998).

\section{Metbods}

\section{Sample}

Two hundred four newborns were recruited for the intervention study between December 1, 1994, and January 31, 1997. Mother-infant dyads were identified by postpartum nursing staff on the basis of (1) positive maternal or infant urine drug screen at birth of the infant and/or (2) medical record documentation of maternal self-report of cocaine and/or opiate used or positive urine drug screen during gestation. Following explanation of the study and the mother signing the Institutional Review Board-approved informed consent, mother-child dyads were randomized to receive home-based nursing intervention or standard pediatric care.

Fifty-eight percent of the mothers reported both cocaine and opiate abuse and 84\% smoked tobacco. During each trimester approximately one quarter $(22 \%-25 \%)$ of the mothers with drug dependence reported occasional (3-4 drinks per week) alcohol use, while $7 \%-8 \%$ reported daily alcohol consumption. Most mothers were single (84.8\%) and African American (96.3\%). The mean gestational age of the infants was 38.4 weeks $(\mathrm{SD}=1.5$ weeks $)$. Mean birth weight was $2817 \mathrm{~g}$ ( $\mathrm{SD}=427 \mathrm{~g})$, mean birth length was $48.3 \mathrm{~cm}(\mathrm{SD}=2.4 \mathrm{~cm})$, and mean head circumference was $32.7 \mathrm{~cm}(\mathrm{SD}=1.4 \mathrm{~cm})$. Birth growth parameters were almost 1 standard deviation below the mean for birth weight and length and almost 1.5 standard deviations below the mean for head circumference (Butz et al., in press).

Children who did not continue in the study were less likely to be in the custody of their biological parent $(n=87)$ than children retained in the study $(n=117)(P<.01)$ (Butz et al., 2001). Children who were lost to follow-up did not differ in gender, race, gestational age, type of IUIDE, maternal age, education, or marital status when compared to children who were maintained in the study (Butz et al., 2001).

\section{Procedures and statistical analysis}

Each infant randomized to the intervention group received 16 home visits. Home visits, conducted by culturally competent community health nurses, were scheduled at $1,2,3,4,6,8$, and 10 weeks and 3, 4, 6, 8, $10,12,15$, and 18 months. Each community health nurse participated in a 3-day training to learn physical examination techniques, techniques for teaching developmental 
information based on the Hawaii Early Learning Program (HELP) (Parks, 1988) and the Carolina Preschool Curriculum (JohnsonMartin, Jens, \& Attermeier, 1986), community resources, and emotional support techniques for mother(s)/caregiver(s) of children with IUIDE. In addition, each mother in the intervention group was encouraged to use a Snugli 1 to 2 hours a day to promote close contact time with their infant (Butz et al., 2001).

Descriptive statistics including frequency distribution, mean, and standard deviation were examined. Differences between study groups were compared using $\chi^{2}$ and $t$ test analysis. All $P$ values used 2 -tailed tests of significance.

\section{Infant outcome}

Internalizing (eg, anxious-depressed behaviors) and externalizing (eg, aggressive) behaviors, as measured by maternal report, were significantly improved in the children who participated in the HUGS home-based nursing intervention versus children with IUIDE without the HUGS program (Butz et al., 2001). There was also a trend toward reduced parent stress in the parents who participated in the HUGS intervention. At 3 years of age, there were no statistically significant mean differences on the Stanford-Binet (Fourth Edition) measure for children with IUIDE who participated in the HUGS intervention compared to control children with IUIDE. Comparison of mean IQ scores for 3-year-old children with drug exposure (mean $=90.0, \mathrm{SD}=$ 8.7) compared to children without drug exposure (mean $=90.9, \mathrm{SD}=8.2$ ) revealed no statistically significant differences (Pulsifer et al., 2004).

\section{DISCUSSION}

Examples of 3 promising intervention programs for pregnant and postpartum women with drug dependence and their children are discussed in this article. The programs initiate interventions from early pregnancy through the immediate postpartum period. All programs endeavored to use communitybased culturally relevant interventions that were tailored to the needs of their adult and child clients.

Interventions included home-based nursing, education, and social services and centerbased evaluations and counseling. Interdisciplinary intervention teams were used in Project STRIVE and the EITC program. Community referrals were provided in all of the interventions.

Data from each of the programs demonstrated statistically significant improvements in maternal/caregiver and child outcomes. Notably, Project STRIVE participants demonstrated improved neonatal birth growth parameters, in addition to improved parent knowledge and reduced depression and corporal punishment. Infants treated in the EITC program documented better-than-expected rates of growth for weight and head circumference. The HUGS Program data suggested that caregivers in the intervention group had less parent-related stress and better perceptions of their children's behavior. Two of the studies, Project STRIVE and the EITC program, were limited by their brief followup periods. Program attrition is also a challenge when providing intervention and evaluation for individuals with drug dependence. Measures to reduce barriers to care, such as culturally competent staff, intensive social work case management, transportation, child care, and convenient community location were helpful in maintaining participant trust and engagement. Further research is necessary to improve retention rates and document long-term effectiveness of these interventions.

In summary, interventions for children with IUIDE require a comprehensive culturally relevant family-oriented approach. Communityand home-based services may improve access to interventions. Intervention strategies, which address the multiple needs of the drug-dependent mother and the child, have the greatest promise in improving overall outcome. 


\section{REFERENCES}

American Academy of Pediatrics Committee on Drugs. (1998). Neonatal drug withdrawal. Pediatrics, 101, 1079-1088.

Azuma, S., \& Chasnoff, I. (1993). Outcome of children prenatally exposed to cocaine and other drugs: A path analysis of three-year data. Pediatrics, 92, 396402.

Bandstra, E. S., Morrow, C. E., Anthony, J. C., Accornero, V. H., \& Fried, P. A. (2001). Longitudinal investigation of task persistence and sustained attention in children with prenatal cocaine exposure. Neurotoxicology and Teratology, 23, 545-559.

Bandstra, E. S., Morrow, C. E., Vogel, A. L., Fifer, R. C., Ofir, A. Y., Dausa, A. T., et al. (2002). Longitudinal influence of prenatal cocaine exposure on child language functioning. Neurotoxicology and Teratology, 24, 297-308.

Bavolek, S. J. (1990). Research and Validation Report of the Adult-Adolescent Parenting Inventory. Park City, UT: Family Development Resources, Inc.

Bayley, N. (1969). Bayley scales of infant development. New York: Psychological Corporation.

Bayley, N. (1993). Bayley scales of infant development (2nd ed.). New York: Psychological Corporation.

Beck, A. T., Ward, C. H., Medelson, M., Mock, J., \& Erbaugh, J. (1961). An inventory for measuring depression. Archives of General Psychiatry, 4, 561-571.

Belcher, H. M. E., Shapiro, B. K., Leppert, M., Butz, A. M., Sellers, S., Arch, E., et al. (1999). Sequential neuromotor examination in children with intrauterine cocaine/polydrug exposure. Developmental Medicine and Child Neurology, 41, 240-246.

Bell, G. L., \& Lau, K. (1995). Perinatal and neonatal issues of substance abuse. Pediatric Clinics of North America, 42, 261-281.

Block, J., Block, J., \& Keyes, S. (1988). Longitudinally foretelling drug use in adolescence: Early childhood personality and environmental precursors. Child Development, 59, 336-355.

Butz, A. M., Lears, M. K., O’Neil, S., \& Lukk, P. (1998). Home intervention for in utero drug exposed infants. Public Health Nursing, 15, 307-318.

Butz, A. M., Pulsifer, M. B., Leppert, M., Rimrodt, S., \& Belcher, H. M. E. (2003). Comparison of intelligence, school readiness, and attention in in-utero drug exposed and non-exposed preschool children. Clinical Pediatrics, 42, 727-739.

Butz, A. M., Pulsifer, M. B., Belcher, H. M. E., Leppert, M., Donithan, M., \& Zeger, S. (in press). Infant head growth and cognitive status at 36 months in children with in-utero drug exposure. Journal of Child and Adolescent Substance Abuse.

Butz, A. M., Pulsifer, M., Marano, N., Belcher, H. M. E., Lears, M. K., \& Royall, R. (2001). Effectiveness of a home intervention for perceived child behavioral problems and parenting stress in children with in utero drug exposure. Archives of Pediatric and Adolescent Medicine, 155, 1029-1037.

Brazelton, T. B. (1984). Neonatal Behavioral Assessment Scale. (Clinics in Developmental Medicine No. 88). London: Spastics International Medical Publications.

Chasnoff, I. J., Anson, A., Hatcher, R., Stenson, H., Iaukea, K., \& Randolph, L. A. (1998). Prenatal exposure to cocaine and other drugs: Outcome at four to six years. Annals of the New York Academy of Sciences, 846, 314-327.

Child Abuse Council. (1992). Parenting Knowledge Scale. Tampa, FL: Author.

Chiriboga, C. A., Brust, J. C. M., Bateman, D., \& Hauser, W. A. (1999). Dose-response effect of fetal cocaine exposure on newborn neurologic function. Pediatrics, 103, 79-85.

Delaney-Black, V., Covington, C., Templin, T., Ager, J., Nordstrom-Klee, B., Martier, S., et al. (2000). Teacherassessed behavior of children prenatally exposed to cocaine. Pediatrics, 106, 728-791.

Department of Health and Human Services. (1995). Improving treatment for drug-exposed infants: Treatment Improvement Protocol (TIP) series (DHHS Publication No. SMA 95-3057). Rockville, MD: Author.

Dubowitz, L., \& Dubowitz, V. (1981). The neurological assessment of the preterm and full-term newborn infant (Clinics in Developmental Medicine No. 79). London: Spastics International Medical Publications.

Finnegan, L. P., Kron, R. E., Connaughton, J. F., \& Emich, J. P. (1975). A scoring system for evaluation and treatment of the neonatal abstinence system: A new clinical and research tool. In P. L. Morselli, S. Garattini, \& F. Sereni (Eds.), Basic and therapeutic aspects of perinatal pharmacology (pp. 139-155). New York: Raven Press.

Forrest, D. C. (1994). The cocaine-exposed infant, Part II: Intervention and teaching. Journal of Pediatric Health Care, 1, 7-11.

Foye, H., \& Sulkes, S. (1990). Fetal and neonatal medicine. In R. E. Behrman \& R. Kliegman (Eds.), Nelson essentials of pediatrics (pp. 1-56). Philadelphia, PA: Saunders.

Frank, D. A., Augustyn, M., Knight, W. G., Pell, T., \& Zuckerman, B. (2001). Growth, development, and behavior in early childhood following prenatal cocaine exposure: A systematic review. Journal of the American Medical Association, 285, 1613-1625.

Goldschmidt, L., Day, N. L., \& Richardson, G. A. (2000). Effects of prenatal marijuana exposure on child behavior problems at age 10. Neurotoxicology and Teratology, 22, 325-336.

Goldschmidt, L., Richardson, G. A., Stoffer, D. S., Geva, D., \& Day, N. L. (1996). Prenatal alcohol exposure and academic achievement at age six: A nonlinear fit. Alcoholism: Clinical and Experimental Research, 20, 763-770. 
Hurt, H., Malmud, E., Betancourt, L. M., Brodsky, N. L., \& Giannetta, J. M. (2001). A prospective comparison of developmental outcome of children with in-utero cocaine exposure and controls using the Battelle Developmental Inventory. Developmental and Behavioral Pediatrics, 22, 27-34.

Johnson-Martin, N., Jens, K. G., \& Attermeier, S. M. (1986). The Carolina curriculum for handicapped infants and infants at-risk. Baltimore: Paul Brookes.

Kaltenback, K., \& Finnegan L. (1986) Neonatal abstinence syndrome, pharmacotherapy and developmental outcome. Neurobehavioral Toxicology and Teratology, 8, 353-355.

Larroque, B., Kaminski, M., Dehaene, P., Subtil, D., Delfosse, M. J., \& Querleu, D. (1995). Moderate prenatal alcohol exposure and psychomotor development at preschool age. American Journal of Public Health, 85, 1654-1661.

Luthar, S. S., Cushing, G., \& Rounsaville, B. J. (1996). Gender differences among opioid abusers: Pathways to disorder and profiles of psychopathology. Drug and Alcobol Dependence, 43, 179-189.

Mayes, L. C., Grillon, C., Granger, R., \& Schottenfeld, R. (1998). Regulation of arousal and attention in preschool children exposed to cocaine prenatally. $A n$ nals of the New York Academy of Sciences, 846, 126139.

Milner, J. S., \& Wimberley, R. C. (1979). An inventory for the identification of the child abusers. Clinical Psychology, 35, 95-100.

Morrow, C. E., Bandstra, E. S., Anthony, J. C., Ofir, A. Y., Xue, L., \& Reyes, M. L. (2001). Influence of prenatal cocaine exposure on full-term infant neurobehav- ioral functioning. Neurotoxicology and Teratology, 23, 533-544.

Parks, S. (1988). HELP at home: Hawaii early learning profile. Palo Alto, CA: Vort Corporation.

Pulsifer, M. B., Radonovich, K., Belcher, H. M. E., \& Butz, A. M. (2004). Intelligence and school readiness in preschool children with prenatal drug exposure. Clinical Neuropsychology, 10, 89-101.

Richardson, G. A., Conroy, M. L., \& Day, N. L. (1996). Prenatal cocaine exposure: Effects on the development of school-age children. Neurotoxicology and Teratology, 18, 627-634.

Richardson, G. A., Ryan, C., Willford, J., Day, N. L., \& Goldschmidt, L. (2002). Prenatal alcohol and marijuana exposure: Effects on neuropsychological outcomes at 10 years. Neurotoxicology and Teratology, 24, 309-320.

Streissguth, A. P., Barr, H. M., Kogan, J., \& Bookstein, F. L. (1996). Understanding the occurrence of secondary disabilities in clients with fetal alcohol syndrome: Final report to the Centers for Disease Control and Prevention on Grant No. RO4/CCRO08515 (Tech. Rep. No. 96-06). Seattle: Fetal Alcohol Drug Unit, University of Washington.

Substance Abuse and Mental Health Services Administration. (2002). Results from the 2001 National Housebold Survey on Drug Abuse: Vol. I. Summary of national findings. (DHHS Publication No. (SMA) 023758). Rockville: Office of Applied Studies, NHSDA Series $\mathrm{H}-17$.

Wilsnack, S. C., Vogeltanz, N. D., Klassen, A. D., \& Harris, T. R. (1997). Childhood sexual abuse and women's substance abuse: National survey findings. Journal of Studies on Alcobol, 58, 264-271.

\title{
Lists of current articles:
} http://depts.washington.edu/isei/iyc/iyc_comments.html

\author{
Back to the list of previous articles: \\ http://depts.washington.edu/isei/iyc/iyc_previous.html
}

